\title{
EVALUATION OF THE SUPPORT TO CARE GIVING BY LOCAL NON- GOVERNMENTAL ORGANISATIONS (NGOS) IN THE KANYE CARE PROGRAMME, BOTSWANA
}

\section{Simon Kang'ethe}

\section{STUDY RATIONALE}

The broad objective of the study was to assess the contribution that caregivers make to CHBC programmes. However, the aim of this paper is to evaluate the extent of support that the Kanye care programme receives from the local NGOs/CBOs in the Kanye region.

\section{OPERATIONAL DEFINITION}

Operationally, the word "caregiver" refers to both the primary caregiver (family caregiver who stays with the sick person most of the time) and the community caregiver, referred to as a "volunteer" in the Botswana context, who moves from house to house to supervise and assist the primary caregiver. The researcher (hence the paper) does not distinguish between these two types of caregivers as they both assist in care giving. However, only primary caregivers were interviewed (primary unit of analysis). The author also uses the three terms "client", "sick person" or "patient" to refer to people living with HIV/Aids and other terminal illnesses. NGOs in this context refers to all the organisations not sponsored or run by the government, and therefore includes all community-based, faith-based, private sector and grassroots organisations.

\section{INTRODUCTION}

The impact of HIV/Aids in Botswana has continued relentlessly to reverse the gains that the country has made in the last three decades (NACA, 2005). This has prompted the government to declare HIV/Aids an emergency and to adopt a multi-sectoral approach to the challenge. This has in turn called for the involvement and concerted efforts of local, national and international organisations in the battle. Yet recently the government of Botswana has recognised the pivotal role that NGOs could play in complementing its efforts in the fight against HIV/Aids. It is therefore timely and imperative to evaluate the impact of NGOs, CBOs and other grassroots organisations on the Kanye care programme. This paper therefore sheds light on the gaps that could be filled by strengthened NGOs and other grassroots organisations and the challenge that their current status poses to the Kanye Community Home-Based Care programme's operations and quality of service delivery (Botswana Network of People Living with HIV/Aids (BONEPWA), 2003).

Globally many governments, especially of the developing world, have continued to partner and seek the support of non-governmental organisations (NGOs), community-based organisations (CBOs), private and private-public organisations and individuals in the fight against HIV/Aids. This is because most governments' resources have been stretched thin as a result of the intensifying epidemic, especially in the last two decades (NACP 38, 1997-2002; WHO, 2002). The call by former President of Botswana, Festus Mogae, for concerted and stakeholder partnerships in the fight against the epidemic puts the NGOs and community organisations at the spot, meaning that Botswana is enlisting their support in the fight against the unrelenting epidemic (Kang'ethe, 2006b; NACA, 2000, 2003). Furthermore, the global call in the 2001 United Nations General Assembly Special Session (UNGASS) for countries to work hard to halt the spread of the epidemic was an appeal to enlist the support of all the organisations, 
donors, private organisations and NGOs to complement and supplement government efforts in the fight against the epidemic (UNAIDS, 2001).

Though NGOs have been found to be robust vehicles of development and community mobilisation in many countries of the world (Kang'ethe, 2006a), Botswana experiences the challenge of having a low number of NGOs, coupled with the fact that the existing ones are skeletal and lacking in capacity to make a strong impact, especially in the care field. This was a consequence of the donor exit upon the country being upgraded to upper-middle income status (BONASO Beat, 2000; Government of Botswana \& UNDP, 2000). The government, however, carries a lion's share of blame for the low performance and skeletal state of the NGOs. It has not done much to mobilise them financially.

As in many countries of the developing world, NGOs in Botswana are perceived as organisations existing to exploit communities, with little or no explicit agenda of supplementing and complementing the government's quest to serve its citizenry. Therefore the NGO requests for funding from the government usually becomes a dragged-out process, leading to the near collapse of their operations, or the slow implementation of their planned activities and services. This is an attitude that the governments of some countries need to change, as NGOs have been found to complement and supplement many governments of the world, especially with governmental policy support and blessings. The role of a private-public organisation, the African HIV/Aids partnerships (ACHAP), in Botswana, for example, has proved that non-governmental organisations or private organisations could change the country's development landscape and tempo. ACHAP is holistically involved in financing the antiretroviral (ARV) roll-out programmes and putting in place a lot of infrastructure pertaining to testing and national access to, and distribution of, ARVs (ACHAP Update, 2005; National Strategic Plan, 2003-2009). The aim of this paper is to discuss and evaluate the extent of support that the Kanye care programme gets from the current NGOs/CBOs in Kanye village.

\section{THEORETICAL FRAMEWORK}

\section{Public-private partnership framework}

Public Private Partnership (PPP) is a framework based on the realisation by many governments of the world that there are some things which the private sector or civil society does best, and others where the public sector has more to offer, and hence the need for coexistence and support to one another, in terms of policy or otherwise (Bariagaber, 2003). This is driven by the belief that high-quality public services that the public want, and increasingly expect, will be forthcoming from the interaction of the two sectors. Though the concept works well in the developed world, the developing countries are also catching up to value the coexistence of both the private and the public sector. The value of NGOs to fill the gaps that the public sector has left, therefore, fits into this framework, though loosely. For example, the good work of the Aids Support Organisation (TASO) in Uganda, the first indigenous non-governmental organisation in Africa to respond to the needs of people living with HIV/Aids, has been emulated and replicated across many parts of the continent (UNAIDS, 2003).

Just as the value of the NGOS in the study area has been found useful by the government and communities, so the public-private partnerships principle (PPP) brings the public and private sectors together in a long-term partnership for mutual benefit (ACHAP Update, 2005). The PPP operates on the understanding that the public and private sectors have distinctive, but potentially complementary, roles to play in the rapidly changing world in which public services need to meet the rising expectations of their customers and the wider community in which 
state-owned businesses or organisations increasingly have to compete in service delivery. However, it has been proven in many countries, especially in the West, that the collaboration of these two sectors is the best way to achieve national goals and the objectives of serving communities. There is therefore a need for all the players to undergo a fundamental paradigm shift of thinking and mindset. It is this thinking that the Botswana government needs to embrace in order to give NGOs optimal space and support to perform well. With this approach, part of the funds it has lent to the International Monetary Fund (IMF) and the World Bank could be utilised in building the capacity of the NGOs, especially those offering important grassroots services such as community care (UNAIDS, 1998).

The PPPs are a key element in most governments' strategy for delivering modern, high-quality public services and promoting many countries' competitiveness. Though the Kanye NGOs and CBOs operate on a small scale, they contribute to and complement the government's task of addressing public challenges. A good example is provided by the Bona Lesedi Drop-in Centre (a CBO), which feeds close to a hundred orphans and vulnerable children (DMSAC Report, 2005). However, even in the PPP, the public sector remains the supervisor. It has to put in place independent regulatory bodies, whose role is to ensure, among other things, that high safety standards are maintained. Despite the skeletal and invisible state of NGOs in Botswana, it is important for the government to keep a supervisory eye on the growth of the NGOs and the private sector, so that they do not compromise on quality. Moreover, PPPs enable the government to tap into the disciplines, incentives, skills and expertise which private sector firms and NGOs have developed in the course of their normal everyday business. This releases the full potential of the people, their knowledge and assets in the public sector. This also enables the government to achieve its objectives better and to focus on those activities (UNAIDS, 1998).

Within this framework the government should take on board the private sector and the NGOs as partners to complement one another in the execution of public services. It is no wonder that where this framework is implemented, the government can step back from the day-to-day management of public enterprises and instead focus on the drivers of long-term value, setting targets and encouraging alliances and partnerships with the private sector and the NGOs. Unfortunately in Botswana the government sees especially the NGOs as competitors rather than complementary organs. Though this perspective is changing, the implementation is still lagging behind. The framework can therefore be applied to advise the Government of Botswana to give space and support to especially the NGOs that have become thin on the ground, yet carrying out very essential services that the government ought to be providing (Kang'ethe, 2007).

On the other hand, the PPP, with its emphasis on productivity, could give either the private organisations, NGOs or the private sector a benchmark to gauge their individual operations. More generally, the government has to show commitment to ensure that all public services, whether provided by the public or private sectors, are accountable to the customers and communities they serve, for example, by monitoring levels of customer satisfaction and holding regular discussions between service providers and representatives of users. It is also important to involve users or consumers of the services (UNAIDS, 1998; Vision 2016, 1997).

\section{METHODOLOGY}

\section{Research design}

A qualitative design was used in the study. This is because the study sought to explore the thinking, feelings and attitudes of the caregivers on their contribution to care giving, and 
examining, evaluating $\mathrm{NGO/CBO}$ support or their contribution to the quality of care giving. This design is appropriate for the study as it facilitates the understanding of the process, in this context the process of care giving, rather than the outcomes. According to Creswell (1994), qualitative research is concerned with the meaning that the respondents attach to what is happening in the field. Qualitative design is concerned with how people make sense of their lives and lived experiences. Participant observation, a common tool of qualitative designs, was also used to capture the mood and perceptions of the caregivers.

\section{Sample selection}

For the sample selection all the 140 registered primary caregivers, as they appeared in the Kanye CHBC register, were selected for inclusion in the study. The participation, contribution and experience of all the registered caregivers were considered important. Eighty-two (59\%) registered primary caregivers, making up 10 focus groups, turned up. The only five CHBC nurses who supervised the $\mathrm{CHBC}$ programme were also included as samples. They were included because of their mandate of supervising the CHBC programme and the caregivers. Their views and opinions served to validate, cross-check, corroborate and confirm those of the caregivers. The size of the focus groups ranged from six to 12. Although all the focus group (FGD) sessions had been scheduled to last between 60 and 90 minutes, the researcher stopped the discussions when saturation point was reached. Each respondent was involved only once in the focus group discussion. The author chose to have only one focus group session in a day in order to make adequate arrangements to ensure that all the participants for the following day's session were adequately prepared. The $\mathrm{CHBC}$ register in each clinic helped to identify the number of the primary caregivers from each clinic and hence made the sample grouping for the FGD easier. The community caregivers (referred to as the volunteers in the Botswana context) also helped to clarify the number of caregivers they were supervising and supporting in their care-giving roles. This eased the process of involving the caregivers in the study.

The selection criteria for the caregivers and their grouping, disregarding age and gender, were based on the proximity of the caregivers' clinic/health post, and from the clinic/health post one was selected. Because of the size of some clinics such as Kanye Main and Kgwatlheng, and therefore clients being served, the number of caregivers constituted more than one focus group discussions. The caregiver respondents were collected from the following clinics: Kgwatlheng, Kanye main, Mafhikana, Dada, Mmamokhasi clinics and Dilolwe and Sebogo health posts, and taken to Miracle Family Christian Centre (MFCC), where focus group discussions were held. However, the CHBC nurses were each interviewed at their place of work.

\section{Research instruments}

The study used two separate but almost similar interview guides to steer 10 focus group discussions with the caregivers and one-to-one interviews with the nurses. Other than the profile section that required the respondents to give her/his demographic details such as age, educational level and gender, all the other questions in the interview schedule/guide were open ended. The two guides used, one for the caregivers and the other for the nurses, differed only slightly. This is because the two sets of responses served to reinforce, corroborate, confirm and cross-check each other. The instruments had been cleansed, refined, tested and their ambiguities removed during the pilot study that preceded the main study.

\section{Ethical and legal requirements}

To ground the research within a socially and legally acceptable ethical environment, all appropriate ethical issues were taken into consideration: informed consent, maintenance of 
confidentiality and anonymity, adequate debriefings, and treating the respondents with all due respect to maintain their integrity and their human rights. Application by the researcher to carry out the research had been submitted to, and approved by, the Health Research and Development Committee (HRDC) board of the Ministry of Health's research unit, and a permit issued. Caregivers were informed in advance of their rights to voluntarily withdraw from the research involvement if they felt uncomfortable with the research proceedings, though no caregiver withdrew (Creswell, 1994; Salkind, 2000). The researcher had also to write a letter to the Southern District Council asking for authority to enter the field to collect data. The letter was attended to by the Southern District Council (SDC) matron, who wrote to all the clinic heads asking them to assist the researcher in his data-collection exercise.

\section{Data analysis, interpretation and bias reduction}

Data from both the focus group discussions with the primary caregivers and one-to-one interviews with the nurses were taped and then transcribed. The huge piles or crude data were sorted, rearranged and reduced to manageable categories and themes using a coding process. This formed the basis of analysis. While quotes, words, analogies, and jotted notes were used to inform the data collection, tables and graphs were used to present the data and therefore the findings. The results from the pilot study involving five caregivers and one nurse that preceded the study had served to remove ambiguities in the instruments and had helped to focus the study. This contributed to a reduction in the study bias and contributed to data reliability and validity. Double translation of the instruments, that is translation from English to Setswana and then from Setswana to English by two independent translators, the two parties coming together to settle on the differences, also helped reduce data and result bias. To further strengthen data reliability and validity, the two interview guides or the instruments used differed only slightly. The two sets of responses were confirmed, contrasted, corroborated and cross-checked against each other.

\section{Research domain}

The data for this article were obtained from empirical research conducted in December 2005 and January 2006 at Kanye village. The village had a population of 40,628 persons, according to the 2001 Botswana National Census (CSO, 2001). The village has a large Seventh Day Adventist (SDA) referral hospital, five clinics and two health posts. A clinic serves a bigger population than a health post. The research domain was chosen because this area was experiencing a high HIV prevalence rate of $25.8 \%$ and was experiencing a progressively rising death toll among the CHBC clients (NACA, 2003).

\section{FINDINGS}

\section{Profile of the volunteer caregivers}

\section{Age, gender and educational dimension of the caregivers}

The findings of the Kanye study indicate that the caregivers' ages ranged from 18 to 85 years, with 46 caregivers ( $56 \%$ of the total caregivers) being 50 years and above; 28 of them were 60 years and above and constituted $34 \%$ of the total caregivers. The study revealed that most caregivers were women and especially those above 60 years were financially challenged, were not adequately strong to stand the care giving demands, and lacked the support of the community-based organisations and NGOs to help them meet their care giving challenges.

Seventy-two (88\%) caregivers were found to have no economic activity to support themselves. Their poverty and psychological disillusionment were demonstrated by some caregivers 
breaking into tears as they explained the economic and social environments in which they performed care. They complained that while clinics lacked many care giving facilities, or they were not reliably available, other Aids service delivery organisations such as NGOs and CBOs in the area that ought to complement the clinics were few, weak and inadequately assisting their care giving process. They decried the lack of working support groups which could provide a platform to share difficulties, pain and experiences that adversely affected their state of care giving.

Sixty-one (74\%) caregivers had either never been to school, or had only primary level education, with only $5 \%$ of the caregivers having tertiary education. Illiteracy was found to contribute to low-care productivity and poverty. This was psychologically disenabling as most of the lowly educated caregivers had problems accessing education on care giving; following the medical and hygiene protocol; and following the disease progression of their clients. On gender, study findings indicate that the Kanye programme had a serious gender-skewed dimension, with 80 (98\%) women and 2 (2\%) men. Women, especially the aging caregivers, called for men and young people generally to consider helping them in care giving.

\section{SKELETAL AND INVISIBLE NGOs/CBOs IN KANYE VILLAGE}

The majority of the caregiver respondents confirmed that care giving as an integral component of the HIV/Aids campaign in Kanye did not enjoy meaningful assistance from the NGOs, CBOs, or private individuals and companies. While close to half the caregivers indicated knowing or having heard of BOCAIP's (Botswana Christian Aids Intervention Programme) Lesedi Counselling Centre, only a few indicated having been assisted by the counselling centre. Close to half of the respondents did not appear to know BOFWA adequately or mention its assistance packages related to care giving and the HIV/Aids campaign generally such as a street jam, condom distribution and demonstration, and testing campaigns (BOFWA $2^{\text {nd }}$ Strategic Plan, 2003-2008). The following sentiments were common in virtually all the discussions:

These organisations (NGOs/CBOs) have only minimal assistance to care giving.

These organisations are only very small and have not adequately marketed themselves to the public. That's why caregivers do not adequately know them.

Some of us have heard of and experienced Lesedi counselling centres'Bible reading and spiritual mainstreaming to our clients and ourselves.

Lesedi Counselling centre is a valuable organisation especially due to its Bible reading to caregivers and their clients.

We understand that BOFWA is for youth. We caregivers may not know its value.

Some of us have heard about BOFWA, but we do not know its mandate.

\section{FEW AND RUDIMENTARY COMMUNITY-BASED ORGANISATIONS IN KANYE}

Almost all the caregivers in the ten focus group discussions reported only knowing a few CBOs that could have been instrumental in assisting in care giving and the HIV/Aids campaign generally. This they said was because of the inadequate number of CBOs, or the fact that those that were being formed were at rudimentary stages of formation and therefore not known, both in terms of their presence and in service delivery. A few indicated knowing and appreciating the Bona Lesedi Drop-In Centre, which had recently been established. However, close to half of them knew the UCCSA's Kgodisong (United Congregation Church of South Africa) Orphan Centre that was usually financed by Masiela Trust, a national NGO assisting orphans and 
vulnerable children (DSMSAC Report, 2005). The Kgodisong orphan centre was known because it had existed for a long time and it was a project of the UCCSA church. Many people in Kanye were members of, or knew about, the UCSSA church. Caregivers indicated knowing that the centre was operating at low capacity because of financial constraints and was helping only a few orphans and vulnerable children. The following sentiments were captured in many of the discussions:

Many CBOs registered in this region are not taking off. We do not know why.

We need government to mobilise these grassroots organisations, especially those that are care based.

We hear that other districts have these grassroots organisations. Our government should facilitate exchange programmes so that our people can learn how to kick-start these organisations.

\section{INADEQUATE ASSISTANCE BY PRIVATE INDIVIDUALS OR COMPANIES}

Close to three quarters of the caregiver respondents reported having had no care giving assistance from either private bodies or private individuals. A few caregivers indicated that local supermarkets such as Green Grocers, Choppies and Desai were sometimes helpful in terms of giving food packages and sometimes clothes to HIV/Aids clients and orphans. However, they indicated that such help package was preferentially given to orphans and vulnerable children before CHBC clients and their caregivers:

The assistance from these supermarkets is infrequent and prioritises orphans and vulnerable children, not $C H B C$ clients and ourselves.

There are only very few private individuals or companies willing to understand the food challenges that caregivers face with their clients.

If the food basket was adequate, we will not desperately be asking or expecting for help from any organisation/individuals or private companies.

\section{INADEQUATE ASSISTANCE BY FAITH-BASED ORGANISATIONS}

More than half of the Kanye research respondents confirmed that the majority of the caregivers did not know or ever experienced any care giving assistance from faith-based organisations. The following kinds of sentiments were made across all the focus groups:

Care-giving assistance is not known to come from faith-based organisations in Kanye.

We have not experienced or heard about churches helping in care giving.

If there is any help from the churches, we do not know, but it could be based on membership. Churches do it that way.

However, a few caregivers admitted and appreciated the central role that some churches were playing in visiting and encouraging the caregivers and their clients in some areas. However, for those who were experiencing the faith-based organisations' assistance reported that churches showed a tendency towards only remembering the orphans and vulnerable children only during the December festivals, when most orphans get Christmas gifts and handouts, forgetting the caregivers and their HIV/Aids clients. Additionally, caregivers confirmed that most churches would only serve members of their congregation. 


\section{NGOs/CBOs PERCEIVED AS RIVALS BY GOVERNMENT}

Close to half of the caregivers alluded to lack of government support in the growth of the NGOs/CBOs. They indicated that the growth of NGOs and CBOs was hampered by lack of money and wondered why they were not getting adequate and meaningful assistance from the government. A few caregivers indicated having knowledge that government was complicating the process of starting community-based organisations. They quoted cases of child organisations which did not have an easy time with the Department of Social and Community Development $(\mathrm{S} \& \mathrm{CD})$, with the latter perceiving the new organisations as proving its own inefficiencies and ineffectiveness in serving the orphans and vulnerable children. On this issue, caregivers made the following comments:

NGOs and CBOs are beset by lack of funds in Kanye and other parts of the country.

Some government departments are not comfortable with the coming of especially new child organisations. Licensing of the new organisations is at the mercy of government.

Caregivers reported that since the government services and support to care programmes were progressively declining because of inadequate provision from the clinics, NGOs/CBOs could be important to bridge this service gap.

\section{INADEQUATE CROSS-REFERRAL SYSTEM AMONG LOCAL CARE-BASED ORGANISATIONS}

About three quarters of the research respondents in the Kanye study indicated that the crossreferral system among the service providers was weak, meaning that caregivers lacked adequate knowledge and information as to where to seek specific assistance. This was clear from the fact that caregivers who were taking care of people living with HIV/Aids and therefore pivotal in fighting Aids did not adequately know the NGOs or CBOs in the area that were instrumental in assisting them. The majority concurred that:

It is only the clinics we know well; other organisations are neither well known to us, nor is their mandate.

\section{FUNDING CHALLENGES TO GRASSROOTS CARE-GIVING ORGANISATIONS}

About a third of the care respondents indicated knowing that government was not funding grassroots organisations that could assist them in their care giving tasks. They conveyed their wish that if government and well-wishers (donors) were to fund care-giving community grassroots projects, the quality of care giving as well as the morale of caregivers could be raised. Caregivers therefore challenged the government to solicit funds for grassroots caregiving organisations. They quoted cases they heard in the country where the government had facilitated assistance for grassroots community-based organisations from global bodies such as the Global Fund and the Melinda Gates and Merck Foundation (ACHAP update, 2005).

\section{DISCUSSIONS OF THE FINDINGS}

Kanye research respondents indicated that the Kanye care programme was seriously gender skewed, with aging being a challenge for most caregivers. Atta and Fidzani (1996) indicate that over $50 \%$ of the caregivers in most of the Botswana CHBC programmes are elderly and usually financially challenged, and may not be able to follow the hygiene protocol in the care process. It would seem that care-giving responsibilities in Botswana, as in many other developing countries, is in the hands of the grandparents, particularly poor grandmothers (Ntozi \& Nakayiwa, 1999; UNAIDS, 1999). Lack of adequate NGOs and CBOs, especially in deep rural 
areas of the developing world, which can complement or fill the gaps left by the governments in care giving means that care giving has to rely predominantly on government and community support (WHO, 2002). According to McDonnel, Brennan and Tarantola (1994), helping the elderly caregivers is critical to avoid the collapse of the informal community networks that continue to be exploited through care giving.

On the low level of education among the caregivers, other studies in Maun by Phorano, Ngwenya and Nthomang (2005) found that most caregivers have a low educational level. Low education has a bearing on the quality of care giving as HIV/Aids and care giving continue to be dynamic. Issues of drug administration, hygiene and palliative care become difficult for those whose educational capacity is adequate. If the study area had adequate number of NGOs, probably some of them would possibly be addressing the challenge of illiteracy through continuous and on-the-job training (Abbat \& Meija, 1988; Nowlen, 1988).

On gender, studies by Munodawafa (1998), Mojapelo, Ditiarafalo, Tau and Dohlie (2001), Jacques and Stegling (2001), and Kang'ethe (2004, 2006a), all in Botswana, found that care giving in Botswana is predominantly a female domain. Since women have other domestic chores as well, usually taking care of families, care giving presents an extra burden. In most parts of developing world this has contributed immensely to the feminisation of poverty (Kelesetse, 1998; UNDP, 1995). In this era of HIV/Aids, the government, civil society bodies and communities should work collaboratively to ensure a societal paradigm shift of attitudes, thinking, belief systems and stereotypes that continue to dictate that care giving is a female preoccupation. Men should participate in care giving alongside women.

The literature generally confirms the concern that most NGOs' effectiveness has been hindered by their skeletal nature and their low operational capacity (UNAIDS, 1998). Kanye NGOs and CBOs were skeletal, meaning that their capacity to serve the communities was low. BOFWA and Lesedi Counselling Centre, for example, were mandated with an array of care giving activities such as counselling, prevention, care and support services, testing, advocacy and general education to the communities. However, their coverage of these areas was low because of their inadequate resources, especially to pay their volunteers. Reliance of these organisations on unpaid volunteers poses a huge challenge to their growth and discharging of their services. According to Kang'ethe (2004, 2006a), the continued reliance of most care programmes on unpaid volunteers has a serious bearing on their motivation and care productivity. The United Nation's Secretary General's report (2003) on women in Southern African countries found that two thirds of care is handled by the elderly and unpaid volunteers, which leads to low care productivity.

However, evidence abounds that most governments of the developing world have not done enough to assist in strengthening the capacities of the NGOs and CBOs (Mulinge \& Mufune, 2003). The governmental bureaucratic red tape in administration and coordination has usually posed huge challenges, impeding NGO growth. In Ethiopia, for instance, the city government lacks proper and effective facilitation, coordination, administration and proper monitoring and mechanisms for NGOs. NGOs and other donor agencies have not been granted land permits in time for the initiation and implementation of developmental projects (Bariagaber, 2003). But NGOs have also been found to present monitoring challenges to most governments of the world. For instance, in the Ethiopian case study by Bariagaber (2003), almost all the NGOs were reluctant to show their detailed plans and performance, sources of budget allocation and expenditure. This has contributed to sour relationship between NGOs and governments, 
compromising any feasible funding arrangements. It is recommended that NGOs/CBOs also put their house in order to attract government and external donor support.

Kanye village was found to have very few CBOs. Even if others could be in the pipeline in the registration process, they are still at rudimentary stages of formation and development. The researcher knows of only a few community-based organisations dealing with orphans, such as the Bona Lesedi Drop-In Centre and the Kgodisong orphanage centre. The role that the Bona Lesedi Drop-In Centre played in feeding and providing psychosocial support to orphans was pivotal in care giving as some of the children living with HIV/Aids and those whose parents were HIV/Aids clients benefited immensely. However, their role could well be felt in the near future, when the organisation becomes known by many members of the community. Regrettably, both the Bona Lesedi Drop-In Centre and the Kgodisong orphanage centres had a very low carrying capacity and made only an insignificant, though important, contribution to society (DMSAC Report, 2005).

The government of Botswana can be held responsible for the slow growth of the NGOs as it has failed to harness and tap the donor support that could facilitate NGO funding. For instance, lack of commitment and slow response to secure and tap donor funds led to the referred Global Funds being returned to the donor unutilised in 2006 and yet many NGOs like BOFWA and BOCAIP's Lesedi Counselling Centre in Kanye had excellent and convincing budget agendas worth funding. However, it is also worth noting that Botswana has suffered serious funding challenges to its NGOs after the country was raised to the level of upper-middle class status. This led to a great donor funding flight (BONASO, 2000; GOB \& UINDP, 2000). It is recommended that the government take responsibility and the initiative to strengthen the NGOs and CBOs. They could be helped to start sustainable income-generating projects. Botswana needs to use some of its finances lent to the international community to bolster these NGOs.

Kanye caregivers indicated the lack of private companies and individuals assisting in their caregiving role. The call in Botswana's Vision 2016 national document to be a just, caring and compassionate society extended the request to those who could help to assist the less fortunate members of the community (Vision 2016, 1997). Caregivers and their clients form part of this deserving group and could be assisted through companies and private individuals complementing the national HIV/Aids response (National Strategic Framework (NSF), 20032009). This will also test and ground the findings by Mensah (1994) and Brourd (quoted in UNAIDS (2000)) that Africans have a good and strong culture of helping distressed members of their own societies. In Kanye the researcher was aware of help packages to vulnerable populations by Standard Bank, Barclays Bank and other organisations such as Choppies and Desai Supermarkets. Unfortunately, the assistance package could go to any needy area of the HIV/Aids campaign and not to address any care-giving gap. It was also infrequent and, given the magnitude of the needy cases, could be insignificant or unnoticeable in the care-giving arena (Kang' ethe, 2006a).

In contrast to the study area, in many other developing countries private organisations and individuals are on the frontline supporting and helping care programmes and the less fortunate members of the society. The Sanpatong CHBC programme in Thailand, for instance, has identified support and acknowledgement from neighbours and community as one of the special needs of the care giving grandmothers (UNAIDS, 1999). In the project school funding - i.e. children's fees, blankets, clothing, food and milk - is provided to families using donated funds and foodstuffs by community members. A donation of approximately U\$17 000 from the Thai Red Cross society, for instance, enabled the project to provide these amenities for two years. 
The Project Hope care programme in Brazil benefits greatly from community support. This is expressed in contributions of materials or services. Fundraising or recreational events often receive free food from local businesses. Local people with cars or trucks donate their time to assist in any care giving activity, including driving patients for medical check ups or treatment, and delivering food and clothing to people unable to come to the centres. The Catholic Aids Action field staff in Namibia visits caregivers as a form of encouragement and recognition. This helps to maintain their morale (Huczynski, 1987; Lawler, 1994; UNAIDS, 1999, 2001).

Though the spirit of company and individual support to care giving and HIV/Aids generally is on the increase in Botswana, advocacy by government and all cadres of community leaders needs to be increased a lot so that adequate help may be forthcoming. Otherwise most caregivers and their clients are in dire need of material and financial support.

Research in Kanye indicates that the role of churches in assisting care giving was not evident. However, in other parts of Botswana the role of faith-based organisations has been commendable. The Catholic Church, for instance, has been pivotal in helping HIV/Aids clients and their caregivers. The media have reported on the bishop of Francistown Catholic vicarage, Frank Nubuash, for instance, playing a robust role in advocacy for the sick and the disadvantaged to be assisted, especially with antiretroviral drugs, without any discrimination based on where one comes from. He has emphasised the role that the church needs to play: giving hope to the hopeless, giving love and providing psychosocial support, and making the church a safe place for those who are endangered by the struggles of life. He has ensured that his flock and others in the community can access the antiretroviral drugs (Kang'ethe, 2007). In the outskirts of Gaborone - Mogoditshane, Mmopane, Metsimotlhabe and Tsolamosese villages - the researcher has seen that the Catholic Church has been involved in the community home-based care programme. It has recruited its own volunteers to visit the clients and their caregivers, giving them love, hope, psychosocial support and counselling. The church programme, through its volunteers, organises and brings together the caregivers and their clients for psychosocial meetings at least one day in a week where Bible sharing takes place, physical exercises are done and a nutritious meal served. The clients are collected from their homes and returned afterwards. The programme works hand in hand with the government community home-based care programme. However, the government-recruited volunteers appear unmotivated in their tasks of visiting the homes of the caregivers and their HIV/AID clients (Lawler, 1994). Therefore, the Catholic Church in these areas perfectly fills in the gap of complementing government services and the national response to HIV/Aids (NSF, 2003-2009). But this is a recent and a unique programme and other faith-based organisations need to follow suit and fulfil the country's Vision 2016 of being a just, compassionate and caring nation. Many churches have been accused of folding their arms and watching HIV/Aids attack their "flock and communities in general" left, right and centre (Kang'ethe, 2007; Vision 2016, 1997).

Although in some quarters the government is beginning to recognise the pivotal role and importance of NGOs as complements in the HIV/Aids campaign and other development agendas (BONEPWA, 2003; UNAIDS, 1998, 2005), it does not generally appear to trust the capacity and goodwill of the NGOs as partners of development. In Botswana there is a perception among the NGOs and civil society generally that the government perceives NGOs, alongside the trade unions, as sympathisers with the opposition politics. This has stifled or discouraged assistance. It has also contributed towards making the NGOs skeletal and ineffective (UNAIDS, 1998). In fact, in most countries of Sub-Saharan Africa, state welfare 
provision is extremely limited and declining. This is because of the poverty consequent on the states' corruption and mismanagement, coupled with countries adhering to the imposed World Bank Structural Adjustment Programmes (SAPs) (Mulinge, 2003) to foster development. Lack of adequate government support to the NGOs in Botswana has been a national issue in that even when the government has enough resources from the donor community, NGOs' funding applications to the government take so long to be processed that programmes run by NGOs nearly collapse. Good examples are provided by the Botswana Family Welfare Organisation (BOFWA) and the Botswana Christian Aids Intervention Programme (BOCAIP) in the country that almost collapsed a few years back, and yet the government had had enough donor funds for the HIV/Aids campaign. This has happened even when these organisations exhibit good, transparent and audited accounts (DMSAC Report, 2005). Ironically, most of these donor grants, like the Global Fund, have been withdrawn by donors because of lack of expenditure by the government. The government of Botswana needs to change its position on, and perception of, the NGOs and see them as vehicles of development with a complementary role to play in the national development process.

Kanye caregivers indicated that the study area suffered from weak cross-referral systems, resulting in information not flowing smoothly among the service beneficiaries such as caregivers. This is a big drawback in this era of HIV/Aids, when resources are inadequate, making it urgent for all organisations to pool resources to maximise and optimise productivity (WHO, 2002). Weak referral systems have the danger of community members starting organisations with objectives already addressed by existing organisations. This could lead to duplication of services and therefore inadequate utilisation and management of resources (Jackson, 2002; WHO, 2002). According to this researcher, the referral system, especially from the clinics to clinics and from the clinics to the Kanye Seventh Day Adventist Church (SDA) referral hospital, was weak (Kang'ethe, 2008). Weak cross-referral could lead to duplication and unhealthy competition between organisations instead of each organisation complementing the others. Collaboration between the NGOs and government in service delivery could possibly reinforce service marketability and therefore improve the organisations' referral process.

The country of Botswana needs to emulate other countries with best practices in governmentNGO collaboration. In Cambodia, for instance, home-care teams made up of staff from government health centres and community-focused NGOS have created strong links with community resources such as community leaders (phum), traditional healers and the members of the Buddhist temples (pagodas). The referral systems link the teams with health centres, hospitals and the three government-run HIV Voluntary Testing and Counselling (VCT) Centres. In Cote d'Ivoire, the centre for socio-medical assistance (CASM), an international faith-based NGO initiated in 1991 by HOPE Worldwide, also fulfils the UNAIDS best practice criteria. CASM works in close collaboration with the ministry of Health, the National Aids Programme and the University Hospital. Commendably, the involvement of persons living with HIV/Aids plays an important part in the centre's prevention and advocacy activities (UNAIDS, 1998).

Botswana has continued to suffer funding blows since it was upgraded to an upper-middle class country in the world economic classification (BONASO Beat, 2000; Government of Botswana \& UNDP, 2000). This implies that Botswana is not a needy country compared to other developing countries. However, reality on the ground as evidenced by the majority of caregivers indicating they are poor and needy confirms that there is a lot of poverty and many grey areas that need to be addressed through NGO/CBO mobilisation and intervention. This is 
also reinforced by the literature, which indicates that close to $50 \%$ of Batswana are poor and live below the poverty line (Botswana Millennium Development Goals, 2004; NACP 38, 19972002). It is apparent that the upgrading by the international community looked at the resources from the strong mining sector and concluded that all was well in the country. Even when funding, either from donors or the government, is forthcoming to the NGOs, there are restrictions imposed on many grants and donations, causing a lot of uncertainties over time. This makes it difficult for NGOs to do long-term planning, improve their services or reach their full capacity (UNAIDS, 1998).

\section{CONCLUSION}

The role and importance of the NGOs and CBOs, coupled with individual and private organisations as vehicles of development, especially in Botswana and other resource-strained countries, cannot be over-emphasised. These organisations, given a good operational political environment and funding, can fill the development gaps and reach areas that the government cannot. Their presence in especially care giving is especially critical in this era of HIV/Aids, when government health facilities are congested, leaving only the options of NGOs and CBOs, and other private organisations to offer community support in the care field. Unfortunately the NGO environment has not been supported well, with government showing some mistrust and therefore refusing to fund them in good time. However, the government attitude is gradually changing. Policies to support NGOs and CBOs should be strengthened in order to help mobilise and assist care giving and the whole HIV/Aids campaign generally in Botswana. The government needs to change its mindset and accept NGOs as complementary organs of the development process.

\section{REFERENCES}

ABBAT, F.R. \& MEIJA, A. 1988. Continuing the education of health workers. Geneva: World Health Organization.

ACHAP. 2005. ACHAP Update. December.

ATTA, J.K. \& FIDZANI, N.H. 1996. Baseline study for community home based care programme for terminally ill HIV/Aids patients in Botswana. NACP 31. Aids STD unit, Gaborone, Botswana.

BARIAGABER, H. 2003. The role of NGOs in the alleviation of urban poverty in Ethiopia: the case of Addis Ababa. In: MULINGE, M. \& MUFUNE, P. 2003. Debt relief initiatives and poverty alleviation. Lessons from Africa. African Institute of South Africa, Pretoria.

BMDG. 2004. Botswana Millennium Development Goals Status Report, 2004. Gaborone, Botswana.

BOFWA 2003. 2nd Strategic plan, 2003-2008. Gaborone.

BONASO BEAT. 2000. Botswana Network of Aids Service Organisations. September. Gaborone.

BONEPWA. 2003. Second National Conference for people living with HIV/Aids. Gaborone.

CRESWELL, J.W. 1994. Research design. Qualitative \& quantitative approaches. New Delhi: Sage Publications.

CSO. 2001. Central Statistics Office. Gaborone: Government Printers. 
DMSAC REPORT. 2005. District Multi-sectoral Aids Committee Report. Presented at Rural Administration Centre (RAC) Council Chambers. November.

GOVERNMENT OF BOTSWANA (GOB) \& UNDP. 2000. Botswana Human Development Report, 2000: towards an Aids-free generation. Gaborone.

HUCZYNSKI, A. 1987. Encyclopaedia of organizational change methods. Brookfield, VT, U.S.: Gower Publishing Co Ltd.

JACKSON, H. 2002. Aids AFRICA. Continent in crises. Safaids, Avondale, Harare, Zimbabwe.

JACQUeS, G. \& STEGling, C. 2001. Panacea or perfidy? Paper presented at the $3^{\text {rd }}$ International Conference on Social Work in Health and Mental Health, July 1-5. Tampere, Finland.

KANG'ETHE, S.M. 2004. Issues and challenges of community home based care in Africa. The case of Botswana. Gaborone: University of Botswana. (Unpublished Masters of Social Work Research Essay)

KANG'ETHE, S.M. 2006a. Contribution of caregivers in community home based care programmes: the case of Kanye, Botswana. Mafikeng campus: University of North West. (Unpublished PhD Dissertation in Social Work)

KANG'ETHE, S.M. 2006b. Spirit of "botho" in care giving arena key to Vision 2016 victory. Mmegi Newspaper, 28th December:7.

KANG'ETHE, S.M. 2007. Churches need to be visible. Botswana Guardian Newspaper, 4 May:8.

KANG'ETHE, S.M. 2008. Challenge that the referral system poses to care giving as exemplified by the Kanye community home based care (CHBC) programme in Botswana. Social Work/Maatskaplike Werk, 44(4):355-368.

KELESETSE, N.M. 1998. Aids, home based care \& the status of women in Botswana: a case study of Mogoditshane. Gaborone: University of Botswana. (BA Thesis in Sociology)

LAWLER, E.E. 1994. Motivation in work organization: San Francisco: Jossey-Bass.

McDONNEL, S., BRENNAN, M., BURNHAM, G. \& TARANTOLA, D. 1994. Assessing and planning home based care for persons with Aids. Health Policy and Planning, 9(4):429-437.

MENSAH, M. 1994. Home based care for people with HIV/Aids. Development in Practice, 4(1):58-62.

MOJAPELO, D., DITIRAFALO, T., TAU, M. \& DOEHLIE, E. 2001. Client satisfaction and providers perspectives of home based care in Kweneng District, Botswana. Unpublished Report, Gaborone.

MULINGE, M.M. \& MUFUNE, P. 2003. Debt relief initiatives and poverty alleviation. Lessons from Africa. African Institute of South Africa, Pretoria.

MULINGE, M.M. 2003. Debt forgiveness initiatives and poverty alleviation in Sub-Saharan Africa: too little, too soon. In: MULINGE, M. \& MUFUNE, P. 2003. Debt relief initiatives and poverty alleviation. Lessons from Africa. African Institute of South Africa, Pretoria.

MUNODAWAFA, D. 1998. Evaluation of CHBC pilot projects in Molepolole and Tutume Sub districts, NACP 41, Aids/STD unit, MOH.

NACA 2000. Botswana 2000 HIV Sero-prevalence and STD Syndrome Sentinel Survey. A Technical Report. 
NACA 2003. Botswana 2003 Second Generation HIV/Aids Surveillance. A Technical Report, December. Gaborone.

NACA. 2005. Botswana Second Generation HIV/Aids Surveillance. A Technical Report, December. Gaborone.

NACP 38. 1997. M.T.P. 11, Botswana HIV and Aids, Second Medium Term Plan. 20022007.

NATIONAL STRATEGIC FRAMEWORK 2003-2009. Botswana National Strategic Framework for HIV/Aids. Republic of Botswana.

NOWLEN, P.M. 1988. A new approach to continuing education for business and the professions. New York: American Council on Education \& Macmillan Publishing Company.

NTOZI, J. \& NAKAYIWA, S. 1999. Aids in Uganda: how has the household coped with the epidemic? In: ORUBULOYE, I.O., CALDWELL, J.C. \& NTOZI, J. (eds) The continuing HIV/Aids epidemic in Africa: response and coping strategies. Health Transition Centre, Australian National University, Canberra: 155-180.

PHORANO, O.M., NTHOMANG, K. \& NGWENYA, B.N. 2005. HIV/Aids home based care and waste disposal in Botswana Society. The Botswana Society Journal, 37:161-178.

SALKIND, N.J. 2000. Exploring resources. Upper Saddle River, N.J.: Prentice-Hall.

UNAIDS. 1998. NGO perspectives on access to HIV-related drugs in 13 Latin American and Caribbean countries. Geneva. Switzerland. UNAIDS.

UNAIDS. 1999. Comfort and hope. Six case studies on mobilizing family and community care for and by people with HIV/Aids, June. Geneva. Switzerland.

UNAIDS. 2000. Caring for carers. Managing stress in those who care for people with HIV and Aids. UNAIDS Case study. May. Geneva. Switzerland.

UNAIDS. 2001. Keeping the promise. Summary of declarations of commitment on HIV/Aids. UNGASS, June. Geneva. Switzerland.

UNAIDS. 2003. Accelerating Action against Aids in Africa. Geneva, Switzerland.

UNAIDS. 2005. Voices of Youth. Botswana Urban Youth Project. Gaborone. Republic of Botswana.

UNDP. 1995. Human Development Report. New York, USA.

UNITED NATIONS. SECRETARY GENERAL'S REPORT. [Online] Available: http:www. unfpa.org/hiv/women/report/chapter4.html [Accessed: 10/07/2005].

VISION 2016. 1997. Towards prosperity for all. Presidential task group for a long term vision for Botswana, September. Gaborone: Government Printers.

WHO. 2002. Community home-based care in resource-limited settings. A framework for action. Switzerland.

\section{INTERNET WEBSITE}

http.www.unfpa.org/hiv/women/report/chapter4.html. Women and HIV/Aids. Confronting the crises. A joint report by UNAIDS/UNFPA/UNIFEM 10th July 2005.

Dr Simon M Kang'ethe is a social worker for Skill Share International and attached to the Botswana Network of People Living with HIV/AIDS (BONEPWA), Botswana. 